\title{
Comparison of Coptotermes formosanus and Coptotermes gestroi (Blattodea: Rhinotermitidae) Field Sites and Seasonal Foraging Activity in Hawaii
}

by

\author{
Nirmala K. Hapukotuwa ${ }^{1} \&$ J. Kenneth Grace ${ }^{1 *}$
}

\section{ABSTRACT}

Field surveys were carried out from January 2010 to June 2011 to record the environmental properties of Coptotermes formosanus Shiraki and $C$. gestroi (Wasmann) (Blattodea: Rhinotermitidae) field sites on the island of Oahu, Hawaii; and to document seasonal patterns in C. formosanus and $C$. gestroi foraging activity. The two field sites selected differed in elevation, soil characteristics, vegetation, and mean temperature and humidity patterns. The C. formosanus colony was located on the Manoa campus of the University of Hawaii, near Miller Hall; while the C. gestroi colony was located $40 \mathrm{~km}$ away at the Barber's Point Horse Stables in Kalaeloa, Oahu (formerly Barber's Point Naval Housing). Mean temperature and humidity were recorded monthly at each field site using a $\mathrm{Hobo}^{\circ}$ data logger (1000-1100h), soil samples were taken from each site and analyzed for physical properties, and vegetation type/s were observed, photographed, and samples brought to laboratory for identification. During each site visit, the number of active termite collection traps (termites present) out of a total of 22 traps per site were counted. The C. gestroi field site was generally warmer than that of C. formosanus. Both termite species exhibited irregular activity throughout the year, although $C$. formosanus was more active in general during cooler months (winter) than C. gestroi; while C. gestroi was generally more active during late spring and summer months. These results, as well as introduction histories, may help to explain C. gestroi distribution patterns in Hawaii.

\footnotetext{
${ }^{1}$ College of Tropical Agriculture \& Human Resources, University of Hawaii at Manoa, 3050 Maile Way, Gilmore 202, Honolulu HI 96822, USA

*Corresponding author. Email: kennethg@hawaii.edu
} 


\section{INTRODUCTION}

The Hawaiian Islands are an archipelago of eight major islands in the North Pacific Ocean, formed by volcanic activity over a hotspot in the earth's mantle. The Hawaiian Island archipelago is the most isolated group of islands on earth. The islands have a climate typical of the edges of the tropical region, with temperatures ranging between $25^{\circ} \mathrm{C}-32^{\circ} \mathrm{C}$. The islands receive most of their rainfall from the trade winds during the winter months (October to April) (Ziegler 2002).

Eight introduced termite species have been recorded in Hawaii (Grace $e t$ al. 2002). Among them, the Formosan subterranean termite, Coptotermes formosanus Shiraki (Blattodea: Rhinotermitidae), was introduced over 100 years ago and is the most economically important and widely distributed insect pest in Hawaii (Tamashiro et al. 1987, Grace et al. 2002). In contrast, the more recently introduced Asian subterranean termite, Coptotermes gestroi (Wasmann), formally known as Coptotermes vastator Light in the Pacific (Yeap et al. 2007), has a very limited and localized distribution on the island of Oahu (Woodrow et al. 2001).

Of the drywood termites (Kalotermitidae), Incisitermes immigrans and Neotermes connexus are long-term residents of Hawaii that are only very rarely found in structural wood (Woodrow et al. 1999), and Cryptotermes brevis is the most severe drywood termite pest. Cryptotermes cynocephalus and Incisitermes minor have limited distributions on the island of Oahu (Grace et al. 2002). A rotten wood termite, Zootermopsis angusticollis (Termopsidae), is known to occur in the Kula region, on the island of Maui (Grace et al. 2002).

C. formosanus is primarily found in subtropical and temperate regions, whereas C. gestroi occurs largely in the tropics (Su 2003, Grace 2006). The distributions of these two species overlap in Florida (Scheffrahn \& Su 2005), Taiwan (Shiraki 1909, Tsai \& Chen 2003, Li et al. 2009), and Hawaii (Swezey 1914, Weesner 1965, Grace 2006). In Hawaii, C. formosanus is distributed throughout the island of Oahu (as well as other islands), while C. gestroi is currently limited to the southwest side of Oahu. Coptotermes gestroi appears to be expanding in distribution on Oahu relatively slowly (Uchima \& Grace 2009; Grace, unpublished observations). 
Uchima \& Grace (2003a) estimated the foraging distance and foraging population size of two C. gestroi colonies on Oahu using the mark-releaserecapture method. The two $C$. gestroi colonies were present in a residence in Kalaeloa, Oahu (formerly Barber's Point Naval Housing) and in the Barber's Point horse stables in Kalaeloa. They estimated the foraging population in the horse stables as $679,193 \pm 120,065$ individuals, foraging area as $287.2 \mathrm{~m}^{2}$ and foraging termite biomass as $1.6 \pm 0.3 \mathrm{~kg}$. The foraging population in the residence in Kalaeloa was estimated as 186,593 $\pm 51,910$ individuals, the foraging area as $10.5 \mathrm{~m}^{2}$ and the foraging termite biomass as $0.5 \pm 0.1 \mathrm{~kg}$. These results suggested that $C$. gestroi may have smaller colonies and foraging areas than $C$. formosanus in Hawaii.

The objectives of the present study were: (1) to record environmental properties of two field sites of $C$. formosanus and C. gestroi in order to obtain a basic idea of their comparative habitats; and (2) to document any seasonal variation in $C$. formosanus and $C$. gestroi foraging activity by checking field collection traps every month.

\section{MATERIALS AND METHODS}

\section{Site Descriptions}

The two field sites of the two different termite species on the Island of Oahu differ in elevation and temperature. For $C$.formosanus, we used a colony near Miller Hall on the Manoa campus of the University of Hawaii $\left(21^{0} 17^{\prime}\right.$ $\mathrm{N}, 157^{\circ} 99^{\prime} \mathrm{W}$; $23.47 \mathrm{~m}$ above sea level; average rainfall $267.21 \mathrm{~cm}$; annual mean temperature $18.61^{\circ} \mathrm{C}$ ). For $C$. gestroi, we used a colony located $40 \mathrm{~km}$ from the Manoa campus, at the Barber's Point Horse Stables (Kalaeloa) ( $21^{0}$ $19^{\prime} \mathrm{N}, 158^{\circ} 02^{\prime} \mathrm{W}$; $9.14 \mathrm{~m}$ above sea level; annual rainfall $53.09 \mathrm{~cm}$; annual mean temperature $24^{\circ} \mathrm{C}$ ).

\section{Field Surveys}

Field surveys were carried out from January 2010 to June 2011. To document environmental properties and seasonal variations in termite activity, temperature and humidity at each site was measured monthly using a $\mathrm{Hobo}^{\circ}$ data logger (1000-1100h), soil samples were taken from each site and analyzed for physical properties, and vegetation type/s were observed, photographed, and samples brought to laboratory for identification. During each monthly 
site visit, the number of active termite collection traps (termites present) was counted. Each site contained 22 wooden box-type termite aggregation traps, after the design of Tamashiro et al. (1973).

\section{RESULTS AND DISCUSSION}

We observed some differences in temperature, humidity, vegetation, soil types and soil water content at the two field sites (Table 1). At Kalaeloa $(C$. gestroi field site), there were a few thorny shrubs (most of the time very dry), high silt content in the soil, low soil water content and relatively high temperature. The C. formosanus field site at the University of Hawaii at Manoa had some vegetation (most of the time wet), low silt content in the soil compared to Kalaeloa, relatively high sand content, high soil water content and a relatively lower temperature than the Kalaeloa field site.

Many studies have correlated climatic variables such as minimum and maximum temperatures and annual rainfall to the range limits of species (Jeffree \& Jeffree 1996, Bullock et al. 2000). Our study presents preliminary data regarding climatic variation between two termite habitats that may help to explain the differences in their distribution on Oahu. Coptotermes gestroi currently has a very limited distribution on the southwest side of Oahu, a region with high temperatures year-round. In temperature, this region may be similar to their natural tropical environment. Arntzen \& Themudo (2008) found that geographical variations in ecological parameters determine the range limit of species. Subtropical C. formosanus is essentially found throughout Oahu, except in high forested areas. According to the research of Grace et al. (2004), C. formosanus colonies may extend large distances by making wider, relatively unbranched, and longer tunnels in the soil than C.gestroi. Also the foraging area of $C$. formosanus colonies appears to be larger than that of $C$. gestroi in Hawaii (Uchima \& Grace 2003a) and C. gestroi colonies may be behaviorally constrained by the presence of $C$. formosanus in the immediate area (Uchima \& Grace 2009). Uchima \& Grace (2003b) also found that the feeding rate of $C$. formosanus was higher than that of $C$. gestroi. Hence, for these various reasons, as well as the history of their introductions, $C$. formosanus exhibits a much broader distribution than C. gestroi on the island of Oahu.

We also observed differences in seasonal activity between $C$. formosanus and C. gestroi (Fig. 1). We did not observe any regular pattern of foraging 
activity (number of active traps) with either species. In the case of $C$. formosanus, however, the greatest number of active traps was observed during winter (December 2010), and it was 13 out of 22 traps. The lowest number

Table 1: Environmental properties of the two field sites (Soil separation test; Sand $(0.05 \mathrm{~mm})$, Silt $(0.002-0.005 \mathrm{~mm})$ and Clay (0.002 or less).

\begin{tabular}{|c|c|c|c|c|c|}
\hline $\begin{array}{l}\text { Species/ } \\
\text { Field site } \\
\text { /Area }\end{array}$ & Vegetation & Soil type/s & $\begin{array}{l}\text { Soil } \\
\text { water } \\
\text { content }\end{array}$ & $\begin{array}{l}\text { Mean Annual } \\
\text { Temperature } \\
\left({ }^{\circ} \mathrm{C}\right)\end{array}$ & $\begin{array}{l}\text { Mean Annual } \\
\text { Humidity (\%) }\end{array}$ \\
\hline $\begin{array}{l}\text { C. gestroi } \\
\text { Kalaeloa } \\
246.75 \mathrm{~m}^{2}\end{array}$ & $\begin{array}{l}\text { Prosopis pallida } \\
\text { (kiawe tree), } \\
\text { Asystasia gangetica } \\
\text { (Chinese violet) }\end{array}$ & $\begin{array}{l}\text { Sand } 4.7 \% \text {, } \\
\text { Silt } 52 \% \text {, } \\
\text { Clay } 14.1 \%\end{array}$ & $6.33 \%$ & 29.81 & 55.23 \\
\hline $\begin{array}{l}\text { C. formosanus } \\
\text { Miller Hall } \\
28.6 \mathrm{~m}^{2}\end{array}$ & $\begin{array}{l}\text { Asystasia gangetica } \\
\text { (Chinese violet), } \\
\text { Murraya paniculata } \\
\text { (mock orange) }\end{array}$ & $\begin{array}{l}\text { Sand } 6.7 \% \text {, } \\
\text { Silt } 26.7 \% \text {, } \\
\text { Clay } 6.7 \%\end{array}$ & $23.66 \%$ & 26.58 & 63.64 \\
\hline
\end{tabular}

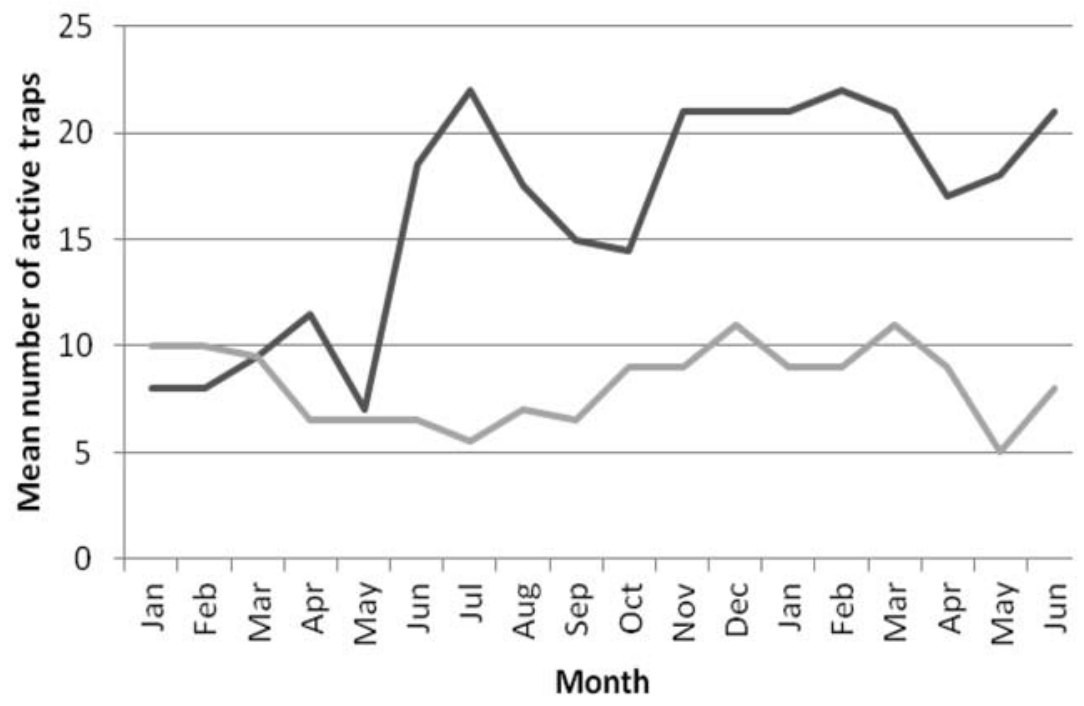

C. gestroi $\longrightarrow$ C. formosanus

Fig. 1. Mean number of active collection traps (out of 22 traps per site) at $C$. formosanus and $C$. gestroi field sites on Oahu, Hawaii, plotted against month from January 2010 -June 2011. 


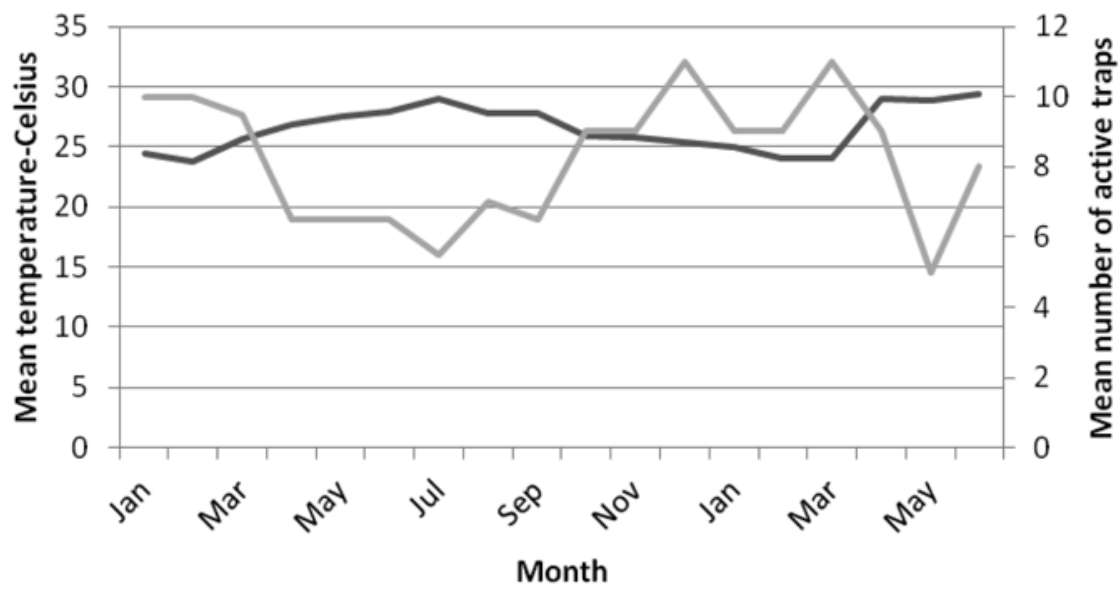

Mean Temperature $\quad$ Mean number of active traps

Fig. 2. Mean number of active collection traps (out of 22 total) at the C. formosanus field site in comparison to mean temperature from January 2010 -June 2011.

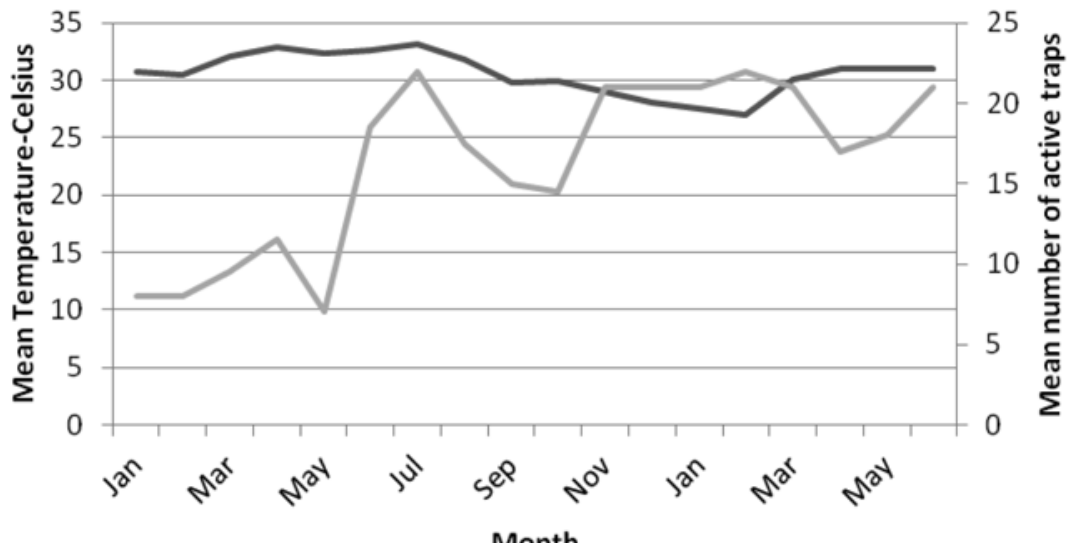

Month

Mean Temperature $\quad$ Mean number of active traps

Fig. 3. Mean number of active collection traps (out of 22 total) at the C. gestroi field site in comparison to mean temperature from January 2010 -June 2011. 
of active traps (5 out of 22) was observed during summer (July 2010 and May 2011). From January to March 2010 and from October 2010 to March 2011, C. formosanus showed a peak activity from 9 - 13 active traps. On the other hand, C. gestroi had greatest activity during summer (July 2010) and spring (February 2011) (all 22 traps active). The lowest active trap number recorded for $C$. gestroi was 7 in January and May 2010. The peak activity periods for C. gestroi were July 2010 and November 2011, with the number of active traps ranging from 21-22.

Fei \& Henderson (2004) reported that temperature and moisture were the most important factors in the distribution of subterranean termites. Bouillon (1970) found that seasonal variations are directly correlated with termite foraging activities. Buxton (1981) also noted that the number of termites in the colony, the production of new individuals and the amount of food already stored in the nest fluctuated according to the season. In contrast, however, Dawes-Gromadzki \& Spain (2003) found no direct relationships between rainfall and termite species richness, or frequency and intensity of attack on baits during a field investigation of seasonal patterns in the activity and species richness of surface-foraging termites at paper baits in a tropical Australian savanna.

Throughout the experimental period (from January 2010 to June 2011) there were fluctuations of temperature and relative humidity at both field sites. Temperature was relatively steady, however, in comparison to relative humidity. At the C. formosanus field site, temperatures ranged from $23{ }^{\circ} \mathrm{C}$ to $30{ }^{\circ} \mathrm{C}$; however, for $C$. gestroi it ranged from $27{ }^{\circ} \mathrm{C}$ to $33{ }^{\circ} \mathrm{C}$ (Figures $2 \&$ 3 ). At the C. gestroi Kalaeloa field site, relative humidity ranged from $46 \%$ to $70 \%$; whereas at the $C$. formosanus Miller Hall site it ranged from $51 \%$ to $80 \%$ (Figs. $4 \& 5$ ).

In conclusion, the $C$. gestroi field site was generally warmer than that of C. formosanus. Both termite species exhibited irregular activity patterns (as represented by the number of active termite collection traps) throughout the year, although $C$. formosanus was more active in general during cooler months (winter) than $C$. gestroi; while $C$. gestroi was generally more active during late spring and summer months. It is worth pointing out that both subterranean termite species distributions and the territory sizes exhibited by individual termite colonies may change in the future as a result of global climate change, 


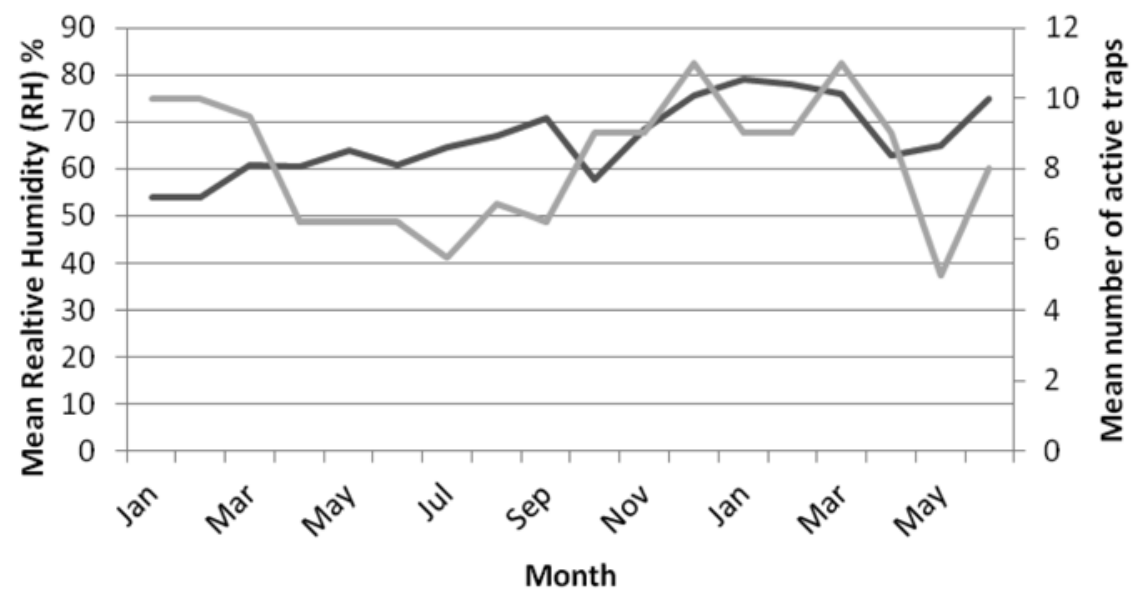

- Mean $\mathrm{RH} \% \quad$ Mean number of active traps

Fig. 4. Mean number of active collection traps (out of 22 total) at the C. formosanus field site in comparison to mean relative humidity from January 2010 -June 2011.

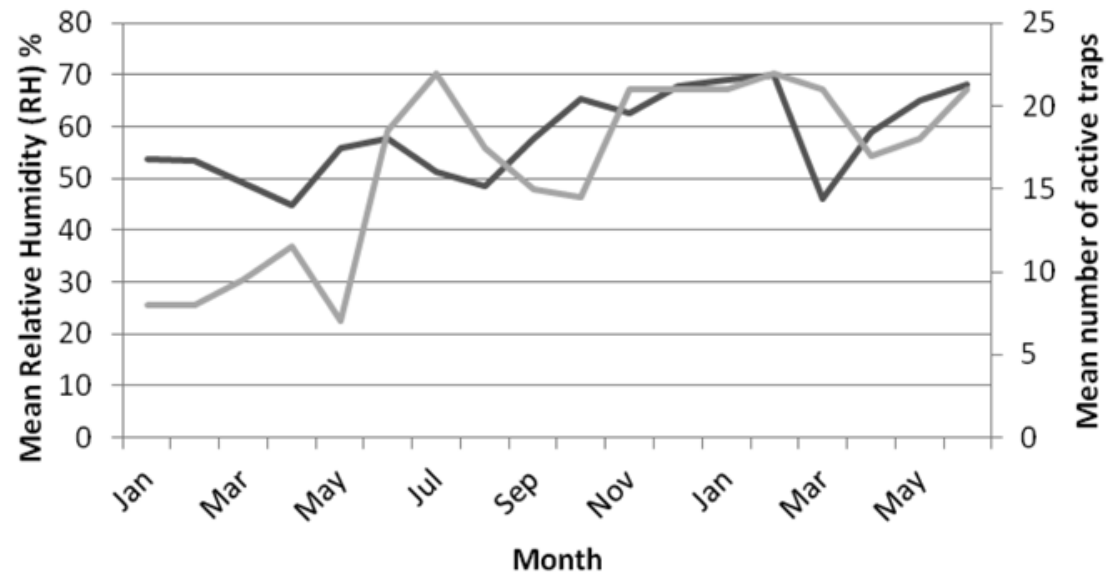

- Mean $\mathrm{RH} \%$ Mean number of active traps

Fig. 5. Mean number of active collection traps (out of 22 total) at the C. gestroi field site in comparison to mean relative humidity from January 2010 -June 2011. 
as recently modeled by Lee $\&$ Chong (2011). However, different temperature preferences as well as different histories of introduction may help to explain both the current limited distribution of C. gestroi in Hawaii, and eventual limits to its future distribution in the islands.

\section{ACKNOWLEDGMENTS}

We are grateful to R. Oshiro, M. Aihara-Sasaki, M. Mason and R. Tong for their help in various ways with the field survey; and to J. R. Yates III, and M. G. Wright for reviewing early drafts of the manuscript. Funding was partially provided by USDA-ARS Specific Cooperative Agreements 58-6615-9-200 and 58-6435-8-294; and McIntire-Stennis and Hatch funds administered by the College of Tropical Agriculture \& Human Resources, University of Hawaii at Manoa.

\section{REFERENCES}

Arntzen, J. W. \& G. E. Themudo. 2008. Environmental parameters that determine species geographical range limits as a matter of time and space. Journal of Biogeography 35 : 1177-1186.

Bouillon, A. 1970. Termites of the Ethiopian region. Pages 153-280 in Krishna and F.M.Weesner, editors. Biology of Termites. Academic Press, New York London.

Bullock, J. M., R. J. Edwards, P. D. Carey \& R. J. Rose. 2000. Geographical separation of two Ulex species at three spatial scales: Does competition limit species' ranges? Ecography 23: 257-271.

Buxton, R. D. 1981. Changes in the composition and activities of termite communities in relation to changing rainfall. Oecologia (Berlin) 51: 371-378.

Dawes-Gromadzki, T.\& A.Spain.2003. Seasonal patterns in the activity and species richness of surface-foraging termites (Isoptera) at paper baits in a tropical Australian savanna. Journal of Tropical Ecology 19: 449-456.

Fei, H. \& G. Henderson. 2004. Effects of temperature, directional aspects, light conditions, and termite species on subterranean termite activity (Isoptera: Rhinotermitidae). Environmental Entomology 33: 242-248.

Grace, J.K. 2006. When invasives meet: Coptotermes formosanus and Coptotermes vastator in the Pacific. Proceedings of the 2006 National Conference on Urban Entomology. Raleigh-Durham, North Carolina; 21-24 May, 2006. Pp. 92-94.

Grace, J. K., M. Aihara-Sasaki \& J. R. Yates. 2004. Differences in tunneling behavior of Coptotermes vastator and Coptotermes formosanus (Isoptera: Rhinotermitidae). Sociobiology 43: 153-158.

Grace, J. K., R. J. Woodrow \& J. R. Yates. 2002. Distribution and management of termites in Hawaii. Sociobiology 14: 87-93. 
Jeffree, C. E. \& E. P. Jeffree. 1996. Redistribution of the potential geographical ranges of mistletoe and Colorado beetle in Europe in response to the temperature component of climate change. Functional Ecology 10: 562-577.

Lee, S.-H. \& T.-S. Chong. 2011. Effects of climate change on subterranean termite territory size: A simulation study.Journal of Insect Science 11(80). Available online: insectscience. org/11.80.

Li, H.-F., Weimin Ye, N.-Y. Su, \& N. Kanzaki. 2009. Phylogeography of Coptotermes gestroi and Coptotermes formosanus (Isoptera: Rhinotermitidae) in Taiwan. Annals of the Entomological Society of America 102: 684-693.

Scheffrahn, R. H. \& N. Y. Su. 2005. Distribution of the termite genus Coptotermes (Isoptera: Rhinotermitidae) in Florida. Florida Entomologist 88: 201-203.

Shiraki, T. 1909. Japanese termites. Transactions of the Entomological Society of Japan 2: 229-242.

$\mathrm{Su}$, N.Y.2003. Overview of the global distribution and control of the Formosan subterranean termite. Sociobiology 41: 7-16.

Swezey, O. H. 1914. Notes and exhibitions. Proceedings of the Hawaiian Entomological Society 3: 27.

Tamashiro, M.,J.K. Fujii \& P.-Y.Lai. 1973. A simple method to observe, trap and preparelarge numbers of subterranean termites for laboratory and field experiments. Environmental Entomology 2: 721-722.

Tsai, C.C. \& C.S. Chen. 2003. First record of Coptotermes gestroi (Isoptera: Rhinotermitidae) from Taiwan. Formosan Entomology 23: 157-161.

Uchima, S. Y. \& J. K. Grace. 2003a. Characteristics of Coptotermes vastator (Isoptera: Rhinotermitidae) colonies on Oahu, Hawaii. Sociobiology 41: 281-288.

Uchima, S. Y. \& J. K. Grace. 2003b. Compartive feeding rates of Coptotermes vastator and Coptotermes formosanus (Isoptera: Rhinotermitidae). Sociobiology 41: 289-294.

Uchima, S. Y. \& J. K. Grace. 2009. Interspecific agonism and foraging competition between Coptotermes formosanus and Coptotermes gestroi (Blattodea: Rhinotermitidae). Sociobiology 54: 765-776.

Weesner, F. W. 1965. The Termites of the United States. The National Pest Control Association, Elizabeth, NJ.

Woodrow, R. J., J. K. Grace \& S. Y. Higa. 2001. Occurrence of Coptotermes vastator (Isoptera: Rhinotermitidae) on the island of Oahu, Hawaii. Sociobiology 38: 667-673.

Woodrow, R. J., J. K. Grace \& J. R. Yates. 1999. Hawaii's termites: an identification guide. College of Tropical Agriculture \& Human Resources, University of Hawaii at Manoa. Household and Structural Pests 1: 0-6.

Yeap, B.-G., A. S. Othman, V. S. Lee \& C.-Y. Lee. 2007. Genetic relationship between Coptotermes gestroi and Coptotermes vastator (Isoptera: Rhinotermitidae). Journal of Economic Entomology 100: 467-474.

Ziegler, A. C. 2002. Hawaiian natural history, ecology and evolution. University of Hawaii Press. 